\section{Knowledge and Attitude of Fertile Women towards Bilateral Tubal Ligation in Port Harcourt, Southern Nigeria}

\section{Abstract}

Background: Bilateral tubal ligation is the commonest method of contraception worldwide; but is yet to gain wide acceptance in Nigeria as a result of many factors. These include ignorance, illiteracy, superstitious beliefs amongst others.

Objectives: To find out the knowledge and attitude of antenatal attendees in University of Port Harcourt Teaching Hospital, towards bilateral tubal ligation.

Methodology: This cross sectional descriptive study involved a coded questionnaire interview of some antenatal mothers at the University of Port Harcourt Teaching Hospital between February and April 2013. Data entry and analysis employed SPSS 15.0 for Windows statistical software.

Results: Most of the respondents were in their third decade of life (59.3\%), nulliparous (64.5\%), and married (97.9\%) with tertiary level of education (69.2\%). Christians dominated the cohort with preponderance of Pentecostals (51.7\%). The knowledge of bilateral tubal ligation amongst the respondents was low. About $52.5 \%$ had never heard of bilateral tubal ligation while only $35.5 \%$ knew the correct meaning of this. Only $18.3 \%$ of the respondents would consider undergoing bilateral tubal ligation in future after completing their family size. The reasons which the respondents gave for never wanting to accept bilateral tubal ligation include permanent nature of the method, fear of operation, and unexpected child loss amongst others. Health personnel/facility was the leading source of information on bilateral tubal ligation.

Conclusion: The low level of knowledge and awareness about bilateral tubal ligation and some of the negative attitudes and views held against it as identified in this study calls for a more comprehensive and concerted effort on information, education and counselling of the citizenry especially women of reproductive age.

Keywords: Knowledge; Attitude; Bilateral tubal ligation; fertile women; Port Harcourt; Southern Nigeria.
Enyindah CE*, Hassan KO, Ojule JD and Oranu EO

Department of Obstetrics and Gynaecology, University of Port Harcourt teaching hospital, Port Harcourt, Rivers State, Nigeria

\section{*Corresponding author: Enyindah CE}

”cosenyi@yahoo.co.uk

Department of Obstetrics and Gynaecology, University of Port Harcourt teaching hospital, Port Harcourt, Rivers state, Nigeria

Tel: +2348033127467

Citation: Enyindah CE, Hassan KO, Ojule JD, Oranu EO (2018) Knowledge and Attitude of Fertile Women towards Bilateral Tubal Ligation in Port Harcourt, Southern Nigeria. J Contracept Stud Vol.3 No.3:19

Received: September 03, 2018; Accepted: September 06, 2018; Published: September 13,2018

\section{Introduction}

Bilateral tubal ligation is an increasingly common method of contraception, and is now the most commonly used method of fertility regulation worldwide [1,2]. Tubal ligation or Tubectomy (also known as having one's "tubes tied") is a surgical procedure for sterilization in which a woman's fallopian tubes are clamped and blocked or severed and sealed, either of which prevents fertilization and subsequent implantation [3]. Tubal ligation is considered a permanent method of sterilization and birth control because of its low failure rate [2-4].
Considering present advances in contraceptive technology, bilateral tubal ligation (BTL) stands out as one of the most efficient, safe and popular method, especially in the developed countries, with an incidence of 28-33. 3\% [5-7]. The incidence of BTL worldwide is rising and in New South Wales, a study revealed that $70 \%$ of sterilization operations were performed for contraceptive management only while $11 \%$ were concurrent with caesarean section [2].

Although the use of bilateral tubal ligation has become the most commonly used family planning method globally, the prevalence 
in Nigeria has continued to be among the lowest in the world with less than $5 \%$ of women over 35 years using this method $[8,9]$. Similarly, while the industrialized countries are using bilateral tubal ligation as a strong and important instrument for improving maternal and infant health and check on the unbridle population growth, the acceptance and practice level is still very low in our continent and Nigeria $[4,10,11]$. There are a number of factors given for this low prevalence in Nigeria. These include inadequate information about the procedure, misconceptions and rumour surrounding the method, number of surviving children, religion and socio-cultural barriers, financial status, inadequate facilities, shortage of trained personnel and poor funding by government [1215]. Despite the fact that family planning is the most cost effective reproductive health input, the government of developing countries earmark less than $0.5 \%$ of their total budget into family planning. Fertility control is a must for any country that strives to develop. Fertility control must be seen as a sensitive and intimate decision which is often based on deeply held religious and philosophical convictions and as such to be approached with sensitivity, empathy, maturity and in a non-judgmental manner [16].

The aim of this study therefore was to find out the knowledge and attitude of antenatal clinic attendees in the University of Port Harcourt Teaching Hospital, Port Harcourt in Southern Nigeria towards bilateral tubal ligation. Antenatal clinic attendees were chosen as the study population because it offers a golden opportunity for effective and efficient forum for exchange of information between pregnant women and health personnel as well as the pregnant women themselves. In addition, it is the group that if properly informed and counselled regarding voluntary female surgical sterilization would in future when they have completed their family size undergo bilateral tubal ligation. This has been demonstrated in previous study carried out by Osuntogun [17] in UCH, Ibadan and Omu and Akagbosu [9] in University of Benin Teaching Hospital where most of the women who were sterilized over stated period were those who were counselled during their antenatal and puerperal period. Port Harcourt capital of Rivers state in Southern Nigeria is cosmopolitan, oil rich and has people from all parts of the country. The population of Port Harcourt was estimated at 1.5 million in 2013 [18]. University of Port Harcourt Teaching Hospital is the apex teaching hospital in the state. It has 800 beds and offers general and specialist care to the citizenry of Rivers State and neighbouring states.

\section{Subjects and Method}

This was a cross sectional descriptive study amongst women attending antenatal clinic at the University of Port Harcourt Teaching Hospital. The data was collected over a three month period. A sample size of four hundred (400) was estimated for the study, and this was arrived by convenience. A systematic random sampling technique was employed and the data gathering instrument used was a structured anonymous self-administered questionnaire. The questionnaires were pretested prior to distribution and necessary corrections made. The authors and experienced Public Health Nurses and Midwives interviewed the subjects who came for antenatal care. A sampling ratio of one in five; starting with the first patient that presented in the clinic for the day was used.

Data collected from the respondents included amongst others, sociodemographic characteristics, reproductive health data as well as their knowledge and attitude towards bilateral tubal ligation.

The data were analysed using SPSS 15.0 Microsoft statistical software. Results were presented as means with standard deviation, rates and proportions in tables and figures. Cross tabulation analysis were performed to establish relationships among variables.

\section{Results}

\section{Sociodemographic characteristics}

A total of four hundred (400) questionnaires were distributed; out of which three hundred and eighty three (383) were completed and retrieved giving a response rate of $95.8 \%$. Most of the respondents (59.3\%) were between 21-30 years and nulliparous 247 (64.5\%). About 375 (97.9\%) were married; while 100 (26.1\%) had secondary education and 265 (69.2\%) tertiary education. Christians dominated the cohort with preponderance of Pentecostals 198 (51.7\%). These are highlighted in the sociodemographic characteristics of respondents shown in Table 1.

Table 1 Demographic characteristics of the respondents.

\begin{tabular}{|c|c|c|}
\hline Characteristics & Number & Percentages \% \\
\hline \multicolumn{3}{|l|}{ Age (Years) } \\
\hline$\leq 20$ & 12 & 3.1 \\
\hline $21-30$ & 227 & 59.3 \\
\hline $31-40$ & 136 & 35.5 \\
\hline$>40$ & 8 & 2.1 \\
\hline \multicolumn{3}{|l|}{ Parity } \\
\hline 0 & 247 & 64.5 \\
\hline $1-4$ & 134 & 35 \\
\hline$>4$ & 2 & 0.5 \\
\hline \multicolumn{3}{|c|}{ Number of Living children } \\
\hline 0 & 247 & 64.5 \\
\hline 1 & 71 & 18.5 \\
\hline 2 & 44 & 11.5 \\
\hline 3 & 16 & 4.2 \\
\hline 4 & 5 & 1.3 \\
\hline \multicolumn{3}{|l|}{ Marital status } \\
\hline Married & 375 & 97.9 \\
\hline Single & 8 & 2.1 \\
\hline \multicolumn{3}{|l|}{ Educational status } \\
\hline No formal education & 2 & 0.5 \\
\hline Primary & 16 & 4.2 \\
\hline Secondary & 100 & 26.1 \\
\hline Tertiary & 265 & 69.2 \\
\hline \multicolumn{3}{|l|}{ Religion } \\
\hline Catholic & 76 & 19.8 \\
\hline Anglican & 65 & 17 \\
\hline Pentecostal & 198 & 51.7 \\
\hline Islam & 44 & 11.5 \\
\hline \multicolumn{3}{|c|}{ Maximum number of children } \\
\hline 1 & 1 & 0.3 \\
\hline 2 & 19 & 5 \\
\hline 3 & 111 & 29 \\
\hline 4 & 188 & 49.1 \\
\hline 5 & 54 & 14.1 \\
\hline 6 & 8 & 2.1 \\
\hline 7 & 2 & 0.5 \\
\hline
\end{tabular}




\section{Knowledge of bilateral tubal ligation}

Table 2 showed that the knowledge of bilateral tubal ligation among the 383 respondents was low. About $52.5 \%$ of the respondents had never heard of bilateral tubal ligation while only $35.5 \%$ knew the correct meaning of bilateral tubal ligation. The knowledge of advantages of bilateral tubal ligation was low among the respondents; only $19.1 \%$ were aware of the fact that it is more effective than other temporary methods of contraception. Out of the 182 respondents who have had about bilateral tubal ligation, only $23.6 \%$ of them knew of someone currently using bilateral tubal ligation while $76.4 \%$ did not know of anyone using it.

\section{Relationship between educational level and Knowledge of correct meaning of bilateral tubal ligation}

Table 3 showed the proportion of the respondents in each educational level that knew the correct meaning of bilateral tubal ligation. Those with tertiary education were $42.6 \%$, followed by secondary education $20.0 \%$ and then primary education $18.8 \%$. Those with no formal education did not know the correct meaning of bilateral tubal ligation.

\section{Relationship between religion and knowledge of correct meaning of bilateral tubal ligation}

Table 4 showed the proportion of respondents in each religious group that knew the correct meaning of bilateral tubal ligation.

Table 2 Knowledge of voluntary female surgical sterilization (BTL).

\begin{tabular}{|l|c|c|}
\hline Knowledge & Number & $\%$ \\
\hline Bilateral tubal ligation & 201 & 52.5 \\
\hline Never heard about it & & \\
\hline Meaning of BTL & 136 & 35.5 \\
\hline The tubes are tied & 37 & 9.7 \\
\hline Womb is tied & 19 & 5 \\
\hline Womb is turned & 7 & 1.8 \\
\hline Tubes are turned & 184 & 48 \\
\hline I don't know & & \\
\hline Advantages of BTL & 74 & 19.1 \\
\hline More effective & 41 & 10.7 \\
\hline Safe & 8 & 4 \\
\hline Cheaper & 39 & 10.2 \\
\hline Does not reduce sexual function & 16 & 3.9 \\
\hline Client can go home on the day of operation & 22 & 5.7 \\
\hline Can be done while awake & 185 & 51.7 \\
\hline I don't Know & & \\
\hline Do you Know anyone using BTL? & $43 / 182$ & 23.6 \\
\hline Yes & $139 / 182$ & 76.4 \\
\hline No & &
\end{tabular}

This was highest amongst the Muslims (38.6\%) followed by the Roman Catholics (36.8\%), Pentecostals (35.8\%) and the Anglicans (30.8\%).

\section{Attitude of respondents towards bilateral tubal ligation}

\section{Likelihood of using bilateral tubal ligation in future}

Figure 1 showed that $18.3 \%$ of the respondents would consider undergoing bilateral tubal ligation in future after completing their family size while $81.7 \%$ would not.

\section{Relationship between educational level and likelihood of using bilateral tubal ligation in future}

Figure $\mathbf{2}$ showed that among the respondents who would consider undergoing bilateral tubal ligation after completing their family size, 55 of them had tertiary level of education; 13 had secondary level of education while 2 had primary level of education. There was none among the respondents with no formal education. Only $20.8 \%$ of all the respondents with tertiary level of education would consider undergoing bilateral tubal ligation in future.

\section{Relationship between religion and likelihood of using bilateral tubal ligation in future}

Figure 3 showed that among the respondents that would consider undergoing bilateral tubal ligation $43.0 \%$ were Pentecostal church Christians followed by Anglicans 21.0\%, Muslims 19.0\% and the least, Roman Catholic Christians $17.0 \%$. This indicates that the Pentecostal Christians more than the Anglicans and Muslims were more likely to undergo bilateral tubal ligation in future. The Roman Catholic Christians were least disposed to this method.

\section{Non-acceptance of bilateral tubal ligation}

The reasons which the respondents gave for never wanting to
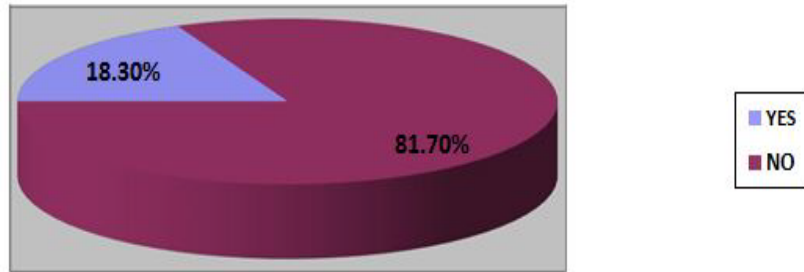

Figure 1 Proportion of respondents who would consider undergoing bilateral tubal ligation after completing their family size.

Table 3 Proportion of respondents in each education group that know the correct meaning of Bilateral Tubal of (BTL).

\begin{tabular}{|l|l|l|l|}
\hline Educational level & No of respondents in the group & No with correct meaning of BTL & \% with correct meaning of BTL \\
\hline No formal Education & 2 & 0 & 0 \\
\hline Primary & 16 & 3 & 18.8 \\
\hline Secondary & 100 & 20 & 20 \\
\hline Tertiary & 265 & 113 & 42.6
\end{tabular}


Table 4 Proportion of respondents in each religious group that know the correct meaning of Bilateral tubal Ligation (BTL).

\begin{tabular}{|l|l|l|l|}
\hline Religion & No of respondents in the group & No with correct meaning of BTL & \% with correct meaning of BTL \\
\hline Muslim & 44 & 17 & 38.6 \\
\hline Roman catholic & 76 & 28 & 36.8 \\
\hline Pentecostal & 198 & 71 & 35.8 \\
\hline Anglicans & 65 & 20 & 30.5 \\
\hline
\end{tabular}

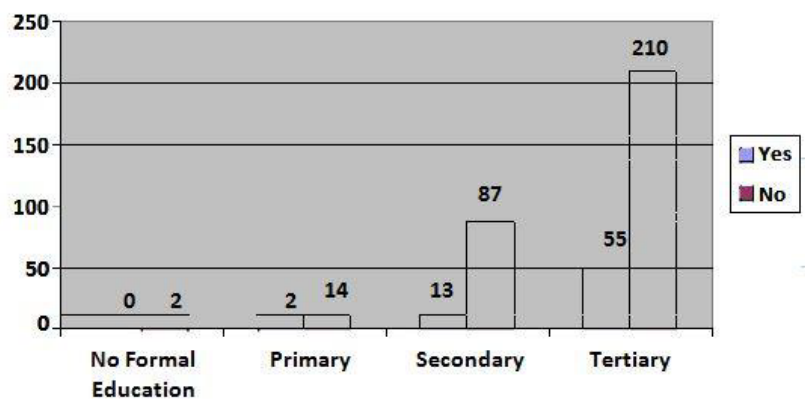

Figure 2 Relationship between educational level and likelihood of using bilateral tubal ligation in future by respondents.
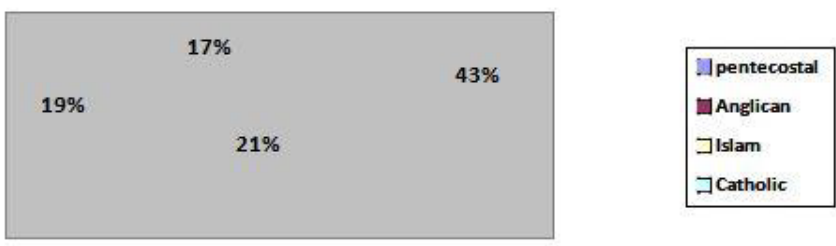

Figure 3 Religion of those who will consider bilateral tubal ligation after completing their family size.

accept bilateral tubal ligation as shown in Figures $\mathbf{4}$ and $\mathbf{5}$ include permanent nature of the method (37.0\%), fear of operation (25.0\%), unexpected child loss $(14.0 \%)$, bad side effects $(10.0 \%)$, religious beliefs $(10.0 \%)$ and undisclosed reason $(4.0 \%)$

\section{Source of Information}

Health personnel/health facility was the leading source of information on contraception (68.1\%). This is followed by electronic media-TV/Radio (21.7\%). Other sources of primary information on contraception were partners (5.2\%), non-specified (2.6\%), school (1.3\%) and friends/siblings (1.1\%).

\section{Discussion}

Our survey revealed that majority of the women was in the third decade of life, nulliparous, married with tertiary level of education. They were more of Christians with Pentecostal background, already had 0-2 living children with a desire to have maximum of four children. Their knowledge of bilateral tubal ligation was low; $52.5 \%$ of the respondents had never heard of bilateral tubal ligation and only $35.5 \%$ of them knew the correct meaning of bilateral tubal ligation. Knowledge of the advantages of bilateral tubal ligation was also low with only $19.1 \%$ of the respondents being aware of its effectiveness. About $31.6 \%$ of those who have heard about bilateral tubal ligation knew someone using this method. This low knowledge and prevalence is in line with
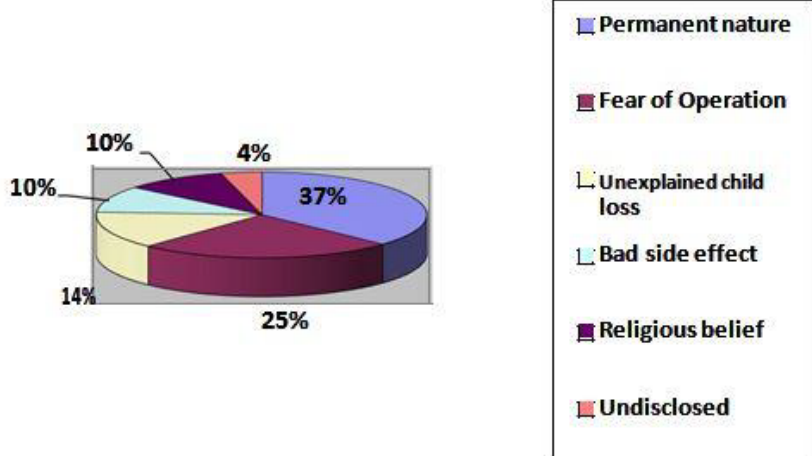

Figure 4 Likely Reason why some respondents would never want to undergo BTL.

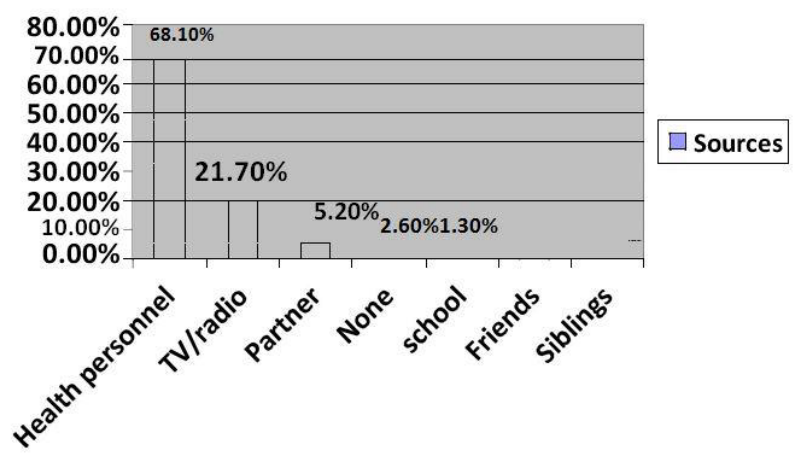

Figure 5 Sources of Information about contraception.

reports from other studies in various parts of Nigeria and Africa [14,19-23].

The knowledge of correct meaning of bilateral tubal ligation was highest among the respondents with tertiary education followed by secondary education with only $2.2 \%$ of those with primary education knowing the correct meaning of bilateral tubal ligation whereas those with no formal education had no clue of this. Lack of formal education as well as poor socioeconomic status of many Nigerian women are recognized obstacles to family planning in Nigeria $[16,17,24]$. The knowledge of correct meaning of bilateral tubal ligation was highest among Christians in Pentecostal Churches and lowest among Muslims. This is with respect to total number of respondents that knew the correct meaning of bilateral tubal ligation. However the proportion of the respondents that knows the correct meaning of bilateral tubal ligation was highest among the Muslims with $38.6 \%$ and lowest among the Anglican Christians $30.8 \%$. The Roman Catholic and Pentecostal Christians were $36.8 \%$ and $35.8 \%$ respectively. This refutes the earlier thought that Islam was opposed to family planning which was 
also emphasized by Omran [25] in 1992. What Islam is opposed to is the use of permanent family planning such as voluntary female surgical sterilization [25]. Roman Catholic churches in the other hand believed strongly that sex is for conception and that use of any artificial means of birth control is sinful. This view is strongly supported by Encyclical Humane Vitae by Pope Paul IV and the Vatican in 1968, also 1993 Encyclical Veritatis splendor by Pope John Paul II, which affirmed the ban of artificial contraception on moral ground. The anti-voluntary female surgical sterilization policies of Roman Catholic and Islamic religion have been seen by some scholars as a demonstration of the lack of understanding of impact of family planning on quality of life and the reduction of very high mortality associated with unwanted pregnancies in many African countries including Nigeria, where lifetime risk of death from pregnancy is greater than 1 in 25 which is far higher than 1 in 5000 seen in Western Europe [26].

After enlightening the respondents with some information regarding voluntary female surgical sterilization, their attitude towards this method was sought for; only $18.3 \%$ of them would consider undergoing bilateral tubal ligation in future after completing their family size. The positive effect of family planning counselling, information, education and communication (IEC) in encouraging better participation in voluntary female surgical sterilization is well documented in some studies done in Nigeria $[9,14,17]$. Other important means of encouraging acceptance of voluntary female surgical sterilization was more positive attitude towards it by the health workers (nurse) some of whom are happy to tell the clients that they too have had bilateral tubal ligation in a study done in Lagos University Teaching Hospital, Nigeria [14]. Communicating the right information and general education regarding voluntary female surgical sterilization will help not only dispel the fears, rumour and misconceptions held against it; also emphasizing the advantages of the method will go a long way in stimulating better participation in voluntary female surgical sterilization.

Over two third of the respondents who would consider undergoing bilateral tubal ligation in this study had tertiary education. Formal education has been shown in studies to have direct effect on

\section{References}

1 Swende TZ, Hwande TS (2010) Female Sterilization by Tubal Ligation at Caeserian section in Markurdi, Nigeria. Ann Afr Med 9: 245-250.

2 Igberase GO, Ebeigbe PN, Umeora OU, Abedi HO (2011) Bilateral Tubal Ligation in a rural hospital in the Niger Delta, Nigeria. Niger $J$ Clin Pract 4: 137-139.

3 https://en.wikipedia.org/wiki/tubal.ligation

4 https://familyplanning.org.nz/advice/contraception/tuballigation.

5 Schmidt E, Diedrich (2014) Surgical Procedures for Tubal Sterilization. Glob libr of women Med.

6 Aisien AO, Oronsaye AU (2007) Two decades of minilaparotomy female sterilization at the University of Benin Teaching Hospital. Niger Postgrad Med J 14: 67-71.

7 WHO Family Planning Worldwide Data Sheet. Population Reference Bureau 2010. maternal mortality by reducing it because educated women tend to make better use of available medical facilities [27]. Education also serves as a way of improving the general socioeconomic status of women in general. On the other hand there is an adverse relationship existing between maternal health (including maternal death) and literacy level [28]. The likelihood of regret after voluntary female surgical sterilization were also similar to those documented in previous study and the reasons include mainly the desire to have more children and unexpected child loss [8]. The data from Nigeria Demographic and Health survey published in 2014, indicate that there is a strong preference for large family size in Nigeria; the total fertility rate of 5.5 children per woman with only $15 \%$ of married women using any method of family planning [29]. Apart from the high premium placed on child birth in Africa; especially in Nigeria there is also the issue of "male child" factor, thus compelling many women who have only female children to continue trying to give birth to a son until they are menopausal or die from obstetric complications. This is a reflection of the mean age for acceptance of sterilization in Nigeria which is as high as 40 years which implies some cultural antipathy to the procedure and possibly fears of child death [30]. Among the major ethnic groups in Nigeria, men dominate in both family and social relationships including right to production and reproduction [31]. Male children are seen as insurance for old age, agent of continuity of the family name and some are necessary to fulfil the priestly duty without which the ancestral spirit will begin to fade or are forgotten [32]. The permanent nature and fear of operation were among the common reasons why the respondents would not want to use voluntary female surgical sterilization in future. These were also noted in previous studies $[8,9,22]$.

\section{Conclusion}

The low level of knowledge and awareness about bilateral tubal ligation and some of the negative attitude and view held against it as identified in this study, calls for more comprehensive and concerted efforts in informing, educating and counselling of Nigerian populace regarding voluntary female sterilization. This hopefully will lead to better acceptance and its utilization as a method of contraception in Nigeria.

8 Otolorin EO, Falase EAO, Olayinka IA, Ladipo OA (1990) Attitude of Nigerians to voluntary sterilization: A survey of an urban population. Trop J Obstet Gynaecol, pp: 18-21.

9 Omu AE, Akagbosu F (1990) Voluntary Surgical Contraception. Attitude, Knowledge and Practices. University of Benin Teaching Hospital Studies. Trop J Obstet Gynaecol 45: 22-26.

10 Sai $F(1994)$ Keynote address of the Product of the International Planned Parenthood Federation on Reproductive Health in developing Countries symposium. Trop J Obstet Gynaecol 11.

11 Pittrof R, Johnson R (1996) Safe Motherhood; an achievable and worthwhile aim. In studd J Progress in Obstetrics and Gynaecology, New York Churchill Livingstone 12: 53-54.

12 National Population Bureau (1984) World Fertility Survey: Nigeria Fertility Survey (1981-82), Principal Report.

13 Omu AE, Unuigbe JA (1990) The Pattern and attitude of Nigerian Women in Benin - City, towards Female Sterilization. Asia-Oceania J Obstet Gynaecol 11: 12-21. 
14 Ogbedengbe OK, Giwa-Osagie OF, Usifoh CA (1990) The Attitude of Fertile Nigerian Women to Sterilization. J Biosoc Sci 7: 135-138

15 Ladipo OA (1995) Sociocultural Barrier to Contraception. Trop J Obstet Gynaecol 12: 1-4.

16 Ojo OA (1995) History of Development of family Planning in Nigeria. Trop J Obstet Gynaecol 12: 48-56.

17 Osuntogun EA (1990) Female Sterilization A General Hospital Experience in Ibadan. Trop J Obstet Gynaecol, pp; 31-32.

18 Kio-Lawson D, Deekor JB (2014) Port Harcourt, The Garden City: A Garden of Resident Nightmares. World Environment 4: 111-120.

19 Aisien AO, Ujah IA, Mutihir JT, Guful F (1999) Fourteen years' experience in voluntary female sterilization through mini laparotomy in Jos, Nigeria. Contraception 60: 249-52.

20 Adetoro 00 (1990) Female Surgical Contraception at the University of Ilorin Teaching Hospital Nigeria. Trop J Obstet Gynaecol 29.

21 Ekwenpu CC (1990) The Realities of Voluntary Surgical Contraception at Zaria - Management, Socio-cultural and Medical Issues. Trop J Obstet Gynaecol 35-36.

22 Akinluyi EM (1990) Voluntary Surgical Contraception Delivery in Nigeria, Streamlining Registration and Minimizing Cost. Benin City. Trop J Obstet Gynaecol, pp: 37-38.

23 Rose JA, Hong S and Huber DH (1985) Voluntary Sterilization: An international fact book. Association for Voluntary Sterilization, New York.

24 Adetoro 00 (1997) Promoting Safe Motherhood Dokita Symposium Proceeds. University College Hospital, Ibadan, pp: 21-23.

25 Omran AR (1992) Family Planning in the Legacy of Islam. London and New York Routledge.

26 Verknyl DA (1993) Two World Religions and Family Planning. The Lancet 342: 473-475.

27 Harrison KA (1985) Childbearing, Health and Social Priorities: A survey of 22774 Consecutive hospital births in Zaria, Northern Nigeria. Br J Obstet Gynaecol 92: 1-119.

28 Briggs ND (1994) Maternal Mortality in sub-sahara Africa. The problems and prevention. Trop J Obstet Gynaecol 11: 8-11.

29 National Population Commission (NPC) Nigeria and ICF International. Nigeria Demographic and Health Survey 2013. Published by National Population Commission (NPC) Nigeria and ICF International, 2014.

30 Briggs ND (1993) Maternal Health, Illiteracy and Maternal Health. Educate or Die. Commentary. Lancet 341: 1063-1064.

31 Isiugo AUC (1994) Reproductive Motivation and Family - Size Preference among Nigeria Men. Studies in Family Planning 25: 149-161.

32 Caldwell JC and Caldwell P (1985) Cultural Forces tending to sustain high fertility in Tropical Africa. World Bank PHN Technical Note 85-86. 